\title{
Research on CA Model of Viral Marketing Diffusion Simulation
}

\author{
Zhou Li \\ Jinan Vocational College, Shandong, Jinan250000 \\ hunter2011@foxmail.com
}

Keywords: Viral marketing, Diffusion simulation, CA model.

\begin{abstract}
As a new marketing model, viral marketing has attracted the attention of academic circles and industrial circles. Viral marketing was applied in Europe and America early, and the application achievement is very evident. But it the application in China is late. With rapid development of internet, the application of viral marketing increases rapidly. The paper makes analysis, comparison and simulation to explore the factors relating to propagation process of viral marketing and find out the method of implementing viral marketing successfully, which provides reference for enterprises in China.
\end{abstract}

\section{Definition of cellular automaton}

The cellular in cellular automaton obeys the same local evolution rule and updates synchronously, which can establish dynamic evolution system in the space. Cellular automaton is not described by strict physical or mathematical equation, and it is an unified name of a type of models.

Cellular automaton can't be described by strict mathematical or physical equation, but as a mathematical model, cellular automaton has strict scientific definition. In the 19202, L.P.Hurd and K.Culik, mathematicians in the USA, made strict description and definition for cellular automaton from the perspective of set theory and topology [25-27].

The paper firstly introduces the definition of one-dimensional cellular automaton. And the definition of high-dimensional cellular automaton can be achieved from the definition of one-dimensional cellular automaton.

There are an infinite amount of cellulars which are distributed on integer lattice point. Each cellular has $\mathrm{K}$ states which are expressed by $0,1, \cdots$ and $\mathrm{K}-1$.

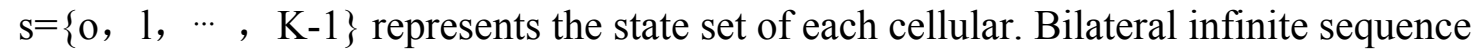

$$
\mathrm{x}=\ldots \mathrm{x}_{-1} \mathrm{x}_{0} \mathrm{x}_{1}, \quad \mathrm{xi} \in \mathrm{S}
$$

is called a configuration of cellular automaton, and the set of all configurations is called configuration space, $\mathrm{S}^{\mathrm{z}}$.

If the time is discrete, for a configuration, each cellular changes at the same time.

$\mathrm{X}^{\mathrm{t}}$ means the configuration of cellular automaton at $\mathrm{t}$, and the configuration at $\mathrm{t}+1$ is decided by $x^{t}$. The state of the $i$ cellular at $t+1$ is decided by the state of the $i$ cellular at $t$ and $2 r$ cellulars with the adjacent distance less than $r$. And the formula is

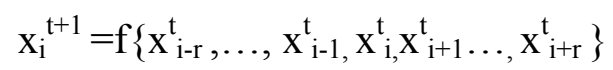

$\mathrm{f}$ has no relationship with $\mathrm{i}$ and t.In fact, $\mathrm{f}$ is a map from $\mathrm{S}^{2 \mathrm{r}+1}$ to $\mathrm{S}$. Using $\mathrm{f}$ can induce the map $\mathrm{F}$ : $\mathrm{S}^{\mathrm{z}} \quad \mathrm{S}^{\mathrm{z}}$, which meets

$$
\mathrm{F}(\mathrm{x})_{\mathrm{i}}=\mathrm{f}\left(\mathrm{x}_{\mathrm{i}-\mathrm{r}}, \ldots, \mathrm{x}_{\mathrm{i}-1}, \mathrm{x}_{\mathrm{i}}, \mathrm{x}_{\mathrm{i}+1}, \ldots, \mathrm{x}_{\mathrm{i}+\mathrm{r}}\right)
$$

In order to be standard, the above description is written to be the following definition.

Definition 1 Map F: $\mathrm{S}^{\mathrm{z}} \longrightarrow \mathrm{S}^{\mathrm{z}}$ is called a cellular automaton. If $\mathrm{r}>0$ and $\mathrm{f}: \mathrm{S}^{2 \mathrm{r}+1} \mathrm{~S}$, any configuration $\mathrm{x}=\ldots \mathrm{x}_{-1} \mathrm{x}_{0} \mathrm{x}_{1} \ldots$ meets

$$
\mathrm{F}(\mathrm{x})_{\mathrm{i}}=\mathrm{f}\left(\mathrm{x}_{\mathrm{i}-\mathrm{r}}, \ldots, \mathrm{x}_{\mathrm{i}-1}, \mathrm{x}_{\mathrm{i}}, \mathrm{x}_{\mathrm{i}+1}, \ldots, \mathrm{x}_{\mathrm{i}+\mathrm{r}}\right)
$$


$\mathrm{f}$ is called local rule of cellular automaton, $\mathrm{r}$ is called radius of neighborhood, and $\mathrm{F}$ is called global rule of cellular automaton.

If cellular automaton is regarded as the evolution of a phenomenon, the local rule can be explained to be that the incidence of an event only relates to the conditions in finite range, and has no relationship with time and place. It indicates that cellular automaton has the feature of locality, steadiness and space homogeneity.

Definition 2 If the radius of neighborhood of cellular automaton is $r=1$, the state data is $k=2$, and state set is $A=\{0,1\}$, the cellular automaton $\mathrm{F}: \mathrm{AZ}$ AZ is the primary cellularatomaton.

\section{CA Model Based on Behavior Difference of the Public Receiving Pathogens}

Response behavior type of the public receiving pathogens. The paper divides the communication process of viral marketing into three stages, contact-application, application-satisfaction, atisfaction-recommendation. In each stage, there are different interference or factors promoting viral marketing. The paper supposes that there are three types of response behaviors of the public receiving pathogens. 1. Satisfied for usage and recommendation. 2. Not satisfied for usage. 3. No usage.

State and variables. Definition 1: The public begin using the received pathogens, and they evaluate the pathogens after usage and feel satisfied. And they actively recommend to the friends, which is called active state.

Definition2: The public begin using the received pathogens, but they are not satisfied. And they are not willing to make any response and don't recommend to other friends, which is called zero state.

Definition 3: The public has no interest in the received pathogens, which is called negative state.

The definition of the paper for the response behavior of the public to the received pathogens is as mentioned above, based on which the paper constructs cellular automaton model of mass behavior. The masses receiving pathogens are cellular space, and each people is regarded as a cellular. Each cellular is influenced by other cellulars, and the behavior of each people is influenced by that of others and influences others. The behavior of each people evolves and updates with the interaction. The influences of cellulars with short distance is greater.

Simulation result and analysis. If the retentivity and transmissibility of audience behavior takes integral randomly in [1, 3], the following situations are simulated. (a)The proportion of the audience of active state, zero state and negative state is 1: 1: 1, and obeys random and average distribution. (b) The proportion of the audience of three states is 4: 4:2, and obeys random and average distribution.

The evolution of the proportion of the audience of initial state, steady state and three states to the total number of audience is shown from Figure 1 to Figure 6 . The black, gray and white in simulation diagram means the audience of active state, zero state and negative state.

From the figures, we can see that the proportion of the audience with different initial states in the audience group decides the final steady state. Under the initial condition of the above(a) (Figure 1), there are the audience with three states in steady state of the audience group (Figure 2). But the audience with the same state tends to the colony (Figure 3), which is the mutual influence result of individuals.

Under the initial condition of the above (b), only there are the audiences of active state and zero state in the final steady state (Figure 4). And the audience of active state disappear in the eight step of evolution (Figure 5), the reason for which is that the proportion of the audience with passive state is smaller than that with other states in the initial state. Under the influence of the audiences with other state, the audience with passive state improves the state. 


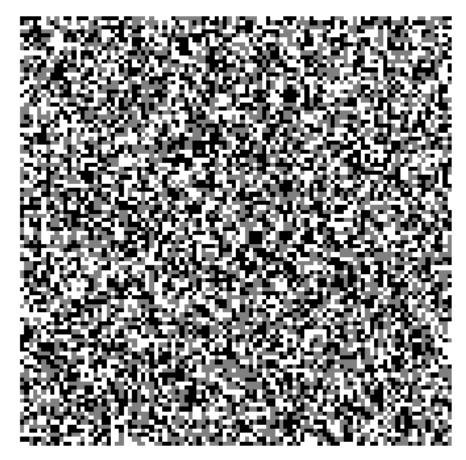

Fig. 1 Active state: zero state: negative state=1: 1: 1 initial average state

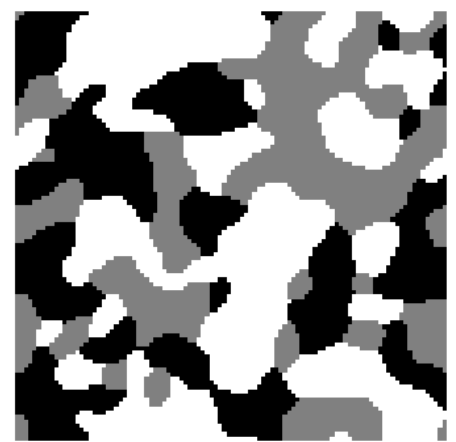

Fig. 2 Active state: zero state: negative state $=1: 1: 1$ the audience group in steady state

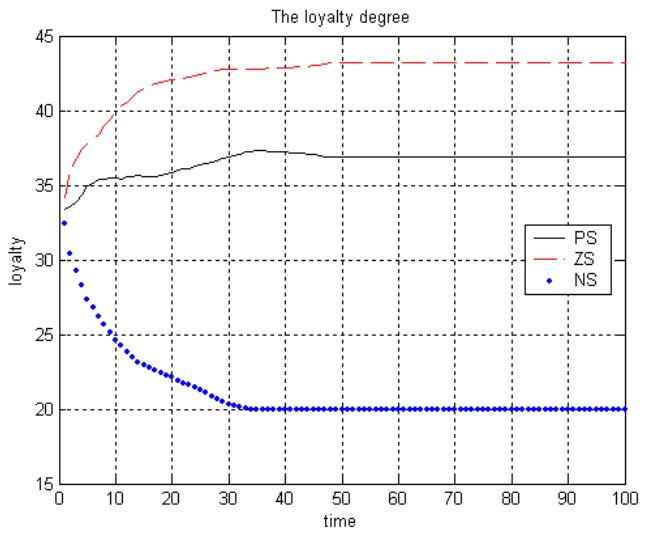

Fig. 3 Evolution process of audience proportion under active state: zero state: negative state=1: 1: 1 the audience group in steady state

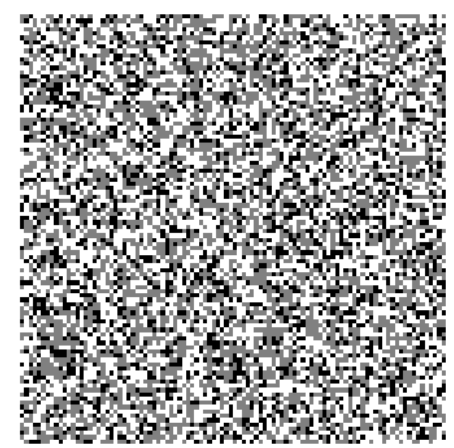

Fig. 4 Active state: zero state: negative state $=4: 4: 2$ initial average state 


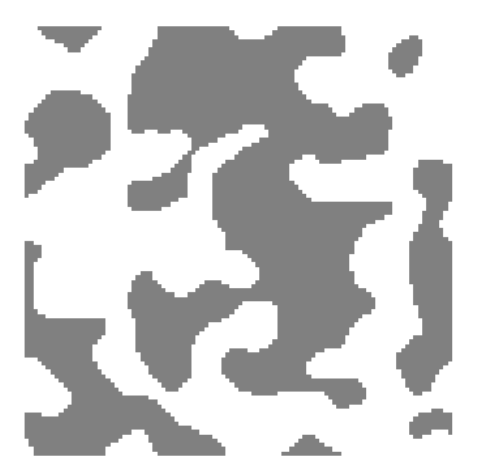

Fig. 5 Active state: zero state: negative state $=4: 4: 2$ the audience group in steady state

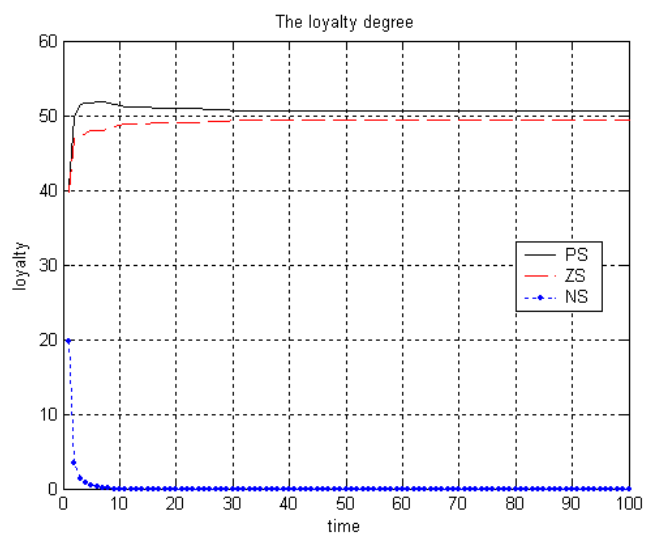

Fig. 6 Initial condition Evolution process of audience proportion under active state: zero state: negative state $=4: 4: 2$

From the above simulation results, we can see that the proportion of the audience under three states in the initial condition is different, which makes the proportion of the audiences after simulation different. The larger the proportion of the audiences with the active state under initial condition, the smaller the proportion of the audiences with negative state in evolution process. When viral marketing scheme is formulated, the audiences of active state should be firstly found out, which can reduce the interference of noise in the process of implementation.

\section{CA Model Based on Purchasing Behavior of Consumers}

Analysis on purchasing behavior of consumers. (1) Purchasing behavior pattern of consumers. Purchasing behavior pattern of consumers means when to buy, where to buy and how to buy after consumers make the decision of purchase.

The starting point of purchasers is stimulus response mode. In psychology, the behavior of people is the response of brain to stimulant. In the process, the behavior of people is dominated by the psychological activity of people. The mode is applied to purchasing behavior of consumers. We can see that after the stimulus of environment and marketing enters the brain, the purchasing process and features of purchasers causes the final purchasing decision, which forms the selection of consumers for products, brand, dealer, purchase occasion and purchase quantity.

(2) Purchase decision process of consumers

Purchase decision process of consumers is the process that purchase motive is transferred into purchase action. When different types of consumption are bought, there are different people participating in the process of purchase decision, so the purchase decision process is different.

Purchase decision process of consumer has direct influence on the final purchase decision. Researching purchase decision process can help marketing personnel to provide service in marketing process and improve marketing efficiency. Generally speaking, a completed purchase decision process consists of requirement, gathering information, evaluation selection, purchase decision and post-purchase evaluation. 
(3) Type of purchase behavior of consumers

When consumers buy different commodities, the difference of complexity of purchase decision is great. Some purchase decisions are easy, but some purchase decisions are complicated, the reason for which is that not only it includes many purchase decision personnel, but also the purchase decision process is long. So before exploring purchasing decision process, it is necessary to divide the type of purchase behavior of consumers. According to decision participation degree of purchaser and difference of product brand, Assal divides the purchase behavior into four types, as shown in Table 1.

Table 1 Type of purchase behavior of consumers

\begin{tabular}{|c|c|c|}
\hline Decision participation degree & High & Low \\
\hline great & Complicated & Multi-variable \\
\hline small & Seeking harmony & Custom \\
\hline
\end{tabular}

Simulation of CA model. Firstly, setting the following input.

(1) influencing degree of the primary group, great, general or no influence.

(2) Number of consumers, $n$.

(3) Type of purchase behavior of consumers, complicated, multi-variable, seeking harmony and custom type.

It generates red, black and blue cellulars, and randomly generates the point representing staff behavior $(\mathrm{t}=0)$. Time stage $\mathrm{t}=1$.

Step 1, moving red, black and blue cellulars.

Step 2, computing $\mathrm{DX}_{\mathrm{fk}}(\mathrm{t}, \mathrm{t}+1)$ and $\mathrm{DX}_{\mathrm{ik}}(\mathrm{t}, \mathrm{t}+1)$, which means the gravitation of secondary group to consumers $\mathrm{k}$ at $\mathrm{t}$, and $\mathrm{DX}_{\mathrm{hk}}(\mathrm{t}, \mathrm{t}+1)$, which means the gravitation of aspirational group to consumers $\mathrm{k}$ at $\mathrm{t}$.

Step 3, moving all points according to shift algorithm.

Step 4, computing dependence degree of consumers to relevant group $Z_{1 \mathrm{kf}}(\mathrm{t})$ and mutual influence degree of consumers $\mathrm{Z}_{2}(\mathrm{t})$.

Step $5, \mathrm{t}=\mathrm{t}+1$, if $\mathrm{t}>\mathrm{m}$, then turning to step 5, else turning to step 1 .

Step 6, the simulation ends.

$$
\begin{aligned}
& Z_{1 k f}(t)=\frac{1}{n} \sum_{k=1}^{n} X_{f k}(t) \\
& Z_{2}(t)=\frac{1}{2} \sum_{k=1}^{n} \sum_{j=1}^{n} X_{k j}(t)
\end{aligned}
$$

The output of simulation includes the dependence degree of consumers on the relevant group $\mathrm{Z}$ $1 \mathrm{kf}(\mathrm{t})$ and the mutual influence degree of consumers $Z 2(\mathrm{t}) . E Z_{1}$ and $E Z_{2}$ is the mean of both, and the computation is as follows.

$$
E \mathrm{Z}_{1}=\frac{1}{m} \sum_{t=1}^{m} \mathrm{Z}_{1 \mathrm{kf}}(t), E \mathrm{Z}_{2}=\frac{1}{2} \sum_{t=1}^{m} \mathrm{Z}_{2}(t)
$$

The management measure with the highest EZ1 and EZ2 is the best marketing scheme.

From the above simulation, the writer thinks that marketing personnel should make efforts to use the influence of relevant group in advertisement, and advertise the satisfaction of each group purchasing a product. And the advertisers hope that there are lots of people recommending the group as relevant group, and they will buy the product. The success of advertising depends on the effect of advertisement on transiting information, product type and sensitivity of individuals to relevant group influence. 


\section{References}

[1] Amoroso S, Patt Y. Decision Procedures for Surjectivity and Injectivity of Parallel Maps for Tes sellation Structures. Computer System Sci,1972,6:448-464.

[2] Brlstor,Julia ${ }^{\wedge}$ L .Enhanced Explanations of Word-of-mouth Communications:The Power of Relationships.Research in Consumer Behavior, 1990,( 4): 51-83

[3] Badii R,Politi A.Complexity:hierarchical structures and scaling in Physics. (Cambridge:Cambridge University press), 1997.

[4] Culikll,L P, Yu S. Computation Theoretic Aspects of Cellular Automata.Physic D, 1990(45):357-378.

[5] Gardner M.The fantastic of John Conway's new solaitaire game life.Scifentific American. 1970,220(4):120.

[6] Nandi, S. and Chaudhuri, P. P. Analysis of periodic and intermediate boundary 90/150 cellular automata [J]. IEEE Trans. Comput. 1996, 45(1): 1-12.

[7] Ulam.S Random Processers and Transformation.Proc. Int. Congr.,1952(2):264 - 275. 